\title{
Perancangan Telescopstick Menggunakan Quality Function Deployment (QFD)
}

\section{Telescopstick Design using Quality Function Deployment (QFD)}

\author{
Deri Teguh Santoso ${ }^{1 *}$, Jojo Sumarjo ${ }^{2}$, Ratna Dewi Anjani ${ }^{3}$ \\ 1,2,3 Program Studi Teknik Mesin, Universitas Singaperbangsa Karawang, Jl. H. S. Ronggowaluyo \\ Telukjambe Timur, Karawang 41361, Indonesia \\ *e-mail: deriteguh2@gmail.com
}

Received: July 3, 2017; Revised: July 22, 2017; Accepted: August 10, 2017

\begin{abstract}
ABSTRAK
Perkembangan ilmu pengetahuan selalu diiringi dengan aplikasi teknologi yang semakin maju, sehingga diperlukan inovasi untuk mendukung implementasi suatu teknologi. Hampir semua pekerjaan maupun aktivitas manusia saat ini dibantu oleh suatu alat. Antena TV merupakan salah satu alat yang hampir dimiliki oleh setiap keluarga di Indonesia. Namun dalam pemasangannya memiliki kesulitan tersendiri dalam pemasangan tiang antena. Maka dari itu merancang suatu alat yang berupa tiang atau stick yang dapat memanjang/memendek secara otomatis sangat diperlukan agar mempermudah dalam penggunaannya. Alat tersebut bernama "Telescopstick". Selain digunakan sebagai alat untuk tiang antena TV, alat ini juga dapat digunakan untuk fungsi lain (multifungsi) karena pada ujung alat ini dibuat joint yang dapat disambungkan dengan alat lainnya, sehingga dapat berfungsi lain seperti pengganti lampu, kemoceng dan lain sebagainya. Alat ini didesain kuat dan ringan yang terbuat dari pipa polyethylene karena mempertimbangkan sebagaimana fungsi dan kebutuhan yang diperlukan alat ini. Cara kerja dari alat ini yaitu menggunakan sistem katrol sehingga dalam pemanjangan/pemendekannya menggunakan pulley atau roller dengan penarikan menggunakan kawat baja. Mekanisme penarikan kawat itu sendiri digunakan motor electric 12 Volt DC dengan energi yang bersumber dari baterai sehingga tidak dilakukan secara manual. Perancangan alat ini menggunakan metode Quality Function Deployment (QFD) karena memfokuskan proses perancangan pada kebutuhan konsumen. Hasil dari perancangan alat ini memperlihatkan bahwa alat ini dapat menggantikan stick konvensional yang mudah hancur dan sulit pemasangannya, serta ketersediaan sparepart yang mudah didapatkan. Diharapkan hasil penelitian digunakan seefektif mungkin pada penelitian selanjutnya.
\end{abstract}

Kata Kunci: Perancangan Telescopstick, Inovasi, Polyethylene, Quality Function Deployment

\begin{abstract}
As the development of science is always accompanied by high-technology applications, innovation is needed to support the implementation of a technology. Almost all human activities are currently assisted by tools. Most of the families in Indonesia has a TV antenna. However, There are difficulties in the installation of antenna stick. Therefore, designing a tool in the form of a stick that can be elongated/shortened automatically is necessary for ease of use. The tool is called "Telescopstick". In addition, to be a tool for TV antenna pole, it is designed for multifunctional purpose because there is a joint at the end of this tool that can be connected with other tools, so it can serve as a substitution of a lamp, duster and etc. This tool is designed to be robust and lightweight, made of polyethylene pipe in a consideration of the functions and needs of this tool. The mechanism of this tool is basically a pulley system that enables the change of its length dimension through the pull of wire. The wire pulling mechanism itself utilizes 12 Volt DC electric motor with energy provided by a battery. Quality Function Deployment (QFD) method is employed to design this tool because it focuses on a consumer-needs-based design process. The results show that the tool can replace conventional sticks which are easily destroyed and difficult to install and the availability of spare parts are easily obtained as well. The findings of this study can be used as effectively as possible for future research.
\end{abstract}

Keywords: Telescopstick Design, Innovation, Polyethylene, Quality Function Deployment 


\section{PENDAhuluaN}

Dalam beberapa tahun terakhir beberapa produsen antena TV hanya berfokus pada spesifikasi pita frekuensi, daya tangkap siaran TV yang baik, dan kabel yang digunakan (Sakti, Purbawanto dan Suryono, 2013), belum adanya keinginan dari produsen untuk memproduksi dan mengembangkan tiang antena sebagai penopang yang baik dalam pemasangannya.

\subsection{Latar Belakang}

Saat ini televisi merupakan sesuatu yang hampir dimiliki semua keluarga di Indonesia. Beberapa teknologi yang berhubungan secara langsung maupun tidak langsung terus dikembangkan dalam upaya meningkatkan kepuasan pengguna layanan televisi. Salahsatu faktor pendukung untuk menikmati layanan televisi yaitu dibutuhkan tiang antena untuk mengkap sinyal pemancar dari stasiun televisi. Ketinggian dari posisi antena televisi menjadi salahsatu faktor yang mempengaruhi daya tangkap sinyal pemancar, sehingga dibutuhkan tiang (stick) sebagai penyangga antena. Selain itu diperlukan stick yang memiliki multifungsi seperti untuk membersihkan bagian atas rumah, memasang lampu, dll. Diperlukan penambahan joint yang berfungsi sebagai penghubung dengan alat tambahan lain Menurut fungsinya stick ini juga diterapkan mekanisme otomatis, untuk mempermudah pemasangan baik untuk memanjangkan atau memendekkan stick.

\subsection{Proses Perancangan}

Langkah awal dalam melakukan proses perancangan yaitu perlu dilakukan identifikasi ide baru atau market need (Ashby, 2011), sampai langkah akhir yaitu spesifikasi lengkap suatu produk yang telah memenuhi ide atau market need, namun tetap dilakukan iterasi antara langkah akhir dengan langkah lanjutan dari market need untuk memastikan proses perancangan sesuai dengan yang telah ditetapkan.

Langkah lanjutan dalam proses perancangan setelah market need yaitu identifikasi concept, embodiment, dan detail. Pemahaman mengenai langkah lanjutan, dapat dilihat pada Gambar 1.

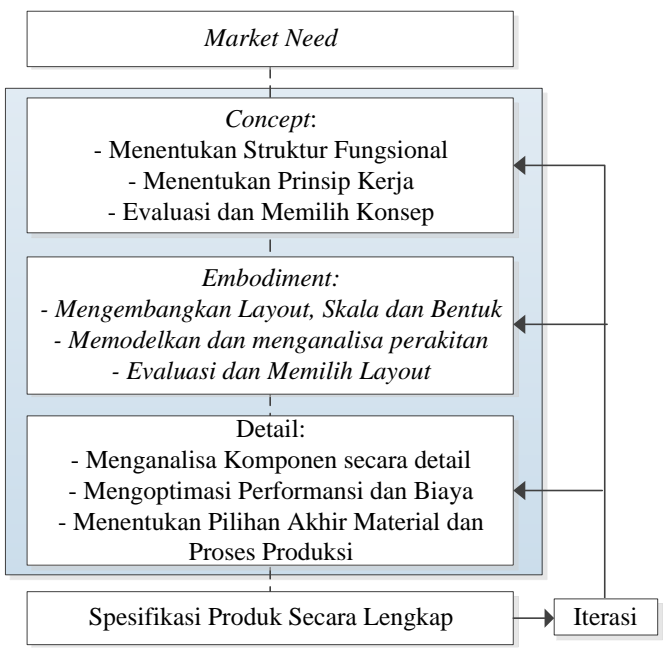

Gambar 1. Flowchart Proses Perancangan Sumber: (Ashby, 2011)

\subsection{Quality Function Deployment}

Langkah awal pada proses perancangan yang ditunjukkan pada Gambar 1 yaitu menentukan market need. Langkah awal dalam penelitian ini menggunakan metode QFD. Metode ini dipilih karena kehandalannya dalam menentukan kebutuhan konsumen.

QFD (Quality Function Deployment) merupakan suatu metode untuk perencanaan dan pengembangan produk yang terstruktur, sehingga development team dapat dengan jelas menentukan keinginan dan kebutuhan konsumen (Cohen, 1995). Beberapa penelitian yang menjadi pembanding, yang membahas mengenai perancangan menggunakan QFD telah dilakukan dengan objek dan kasus yang berbeda, beberapa diantaranya yaitu: desain lemari arsip (Hidayako dan Betanursanti, 2017), dan rancangan meja dapur multifungsi (Anggraeni, Desrianty dan Yuniar, 2013).

\section{METODOLOGI}

Gambar 2 menunjukkan flowchart metodologi penelitian yang digunakan dalam perancangan Telescopstick. Flowchart menunjukkan algoritma yang diawali dengan identifikasi kebutuhan atau sesuai dengan kebutuhan customer (market needed), dilanjutkan dengan pembuatan concept yang output berupa tabel House of Quality (HOQ), kemudian dilanjutkan terus sampai tahap 
detail, sehingga diharapkan setiap tahapan yang telah dilalui dapat memenuhi kriteria yang telah ditentukan sebelumnya (market needed).

\subsection{Komponen Material}

Beberapa komponen yang digunakan dalam penelitian ini merupakan komponen yang mudah didapat di pasaran (common parts) sehingga dalam perawatannya dapat diganti dengan mudah apabila terjadi kerusakan serta ada beberapa komponen yang customize dikarenakan ukuran komponen yang tidak ada dipasaran, komponen yang termasuk common parts dan customize yaitu: 1. Pipa, yang berfungsi selain sebagai pengganti tiang bambu atau besi, juga sebagai alat bantu tambahan (multifungsi) sehingga kriteria yang diinginkan yaitu isolator, kuat, keras, dan ringan, sehingga dalam pemilihan material dimungkinkan polimer dalam kategori polimer thermoplastic, karena memiliki berat jenis dan isolator yang baik.

2. Pulley, prinsip kerja pulley sama dengan tuas, yaitu mengubah arah gaya sehingga kerja yang dilakukan menjadi lebih mudah, oleh sebab itu dapat mengangkat benda-benda yang lebih berat diangkat jika tanpa menggunakan katrol. Kriteria yang diinginkan yaitu material yang ringan namun kuat.

3. Poros, dalam fungsinya dipasangkan dengan pulley, dalam perencanaannya mempertimbangkan kriteria kuat, ringan, dan murah.

\section{HASIL DAN PEMBAHASAN}

Menurut ASI (American Supplier Institute) terdapat empat tahap dalam membuat model QFD, yaitu:

a. Tahap Perencanaan Produk. Tahap ini dikenal dengan House of Quality, yang terdiri dari Customer Need and Benefits, Technical Responses, serta Technical Correlations. Customer Needs and Benefits atau dikenal dengan Customer Requirements, merupakan kelanjutan dari langkah Problem Formulation. HOQ dapat dilihat pada Gambar 3.

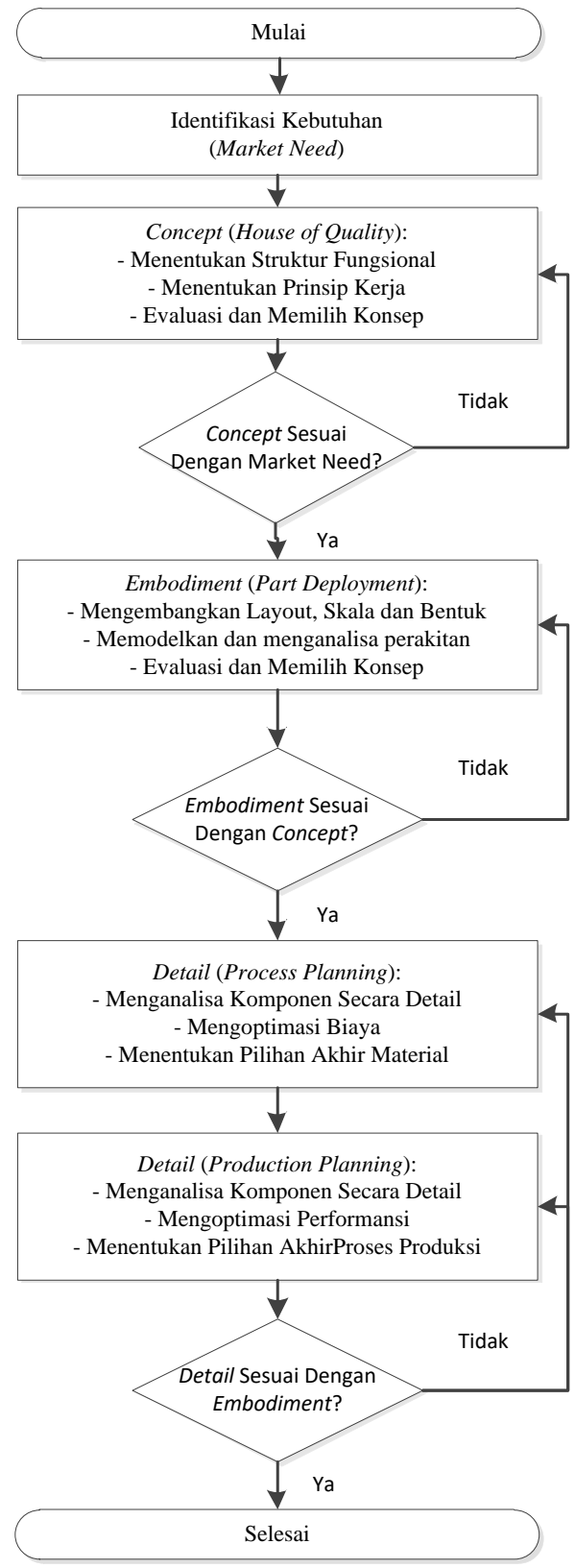

Gambar 2. Flowchart Metodologi Penelitian

b. Tahap Perencanaan Komponen. Tahap ini dikenal dengan Part Deployment, yaitu pemilihan material setiap komponen yang digunakan sehingga sesuai dengan langkah problem formulation.

1) Pipa. Telah dijelaskan pada bagian 2 , bahwa berdasarkan fungsinya pipa dipilih yaitu mengacu pada kriteria tidak menghantarkan listrik (isolator). Pipa di Indonesia, material pipa yang memenuhi dan banyak beredar yaitu hanya dua tipe dari kategori polimer, yaitu pipa HDPE (High Density 
Polyethylene), dan PVC (Polyvinylchloride).

Berdasarkan Tabel 1, material HDPE lebih unggul dalam pemilihan material, karena nilai Electrical Resistivity yang rendah mengakibatkan sifat isolator yang baik, Density yang lebih rendah dan Cost yang rendah pula, sehingga pada pemilihan pipa, mateial polimer jenis HDPE menjadi pilihan utama.

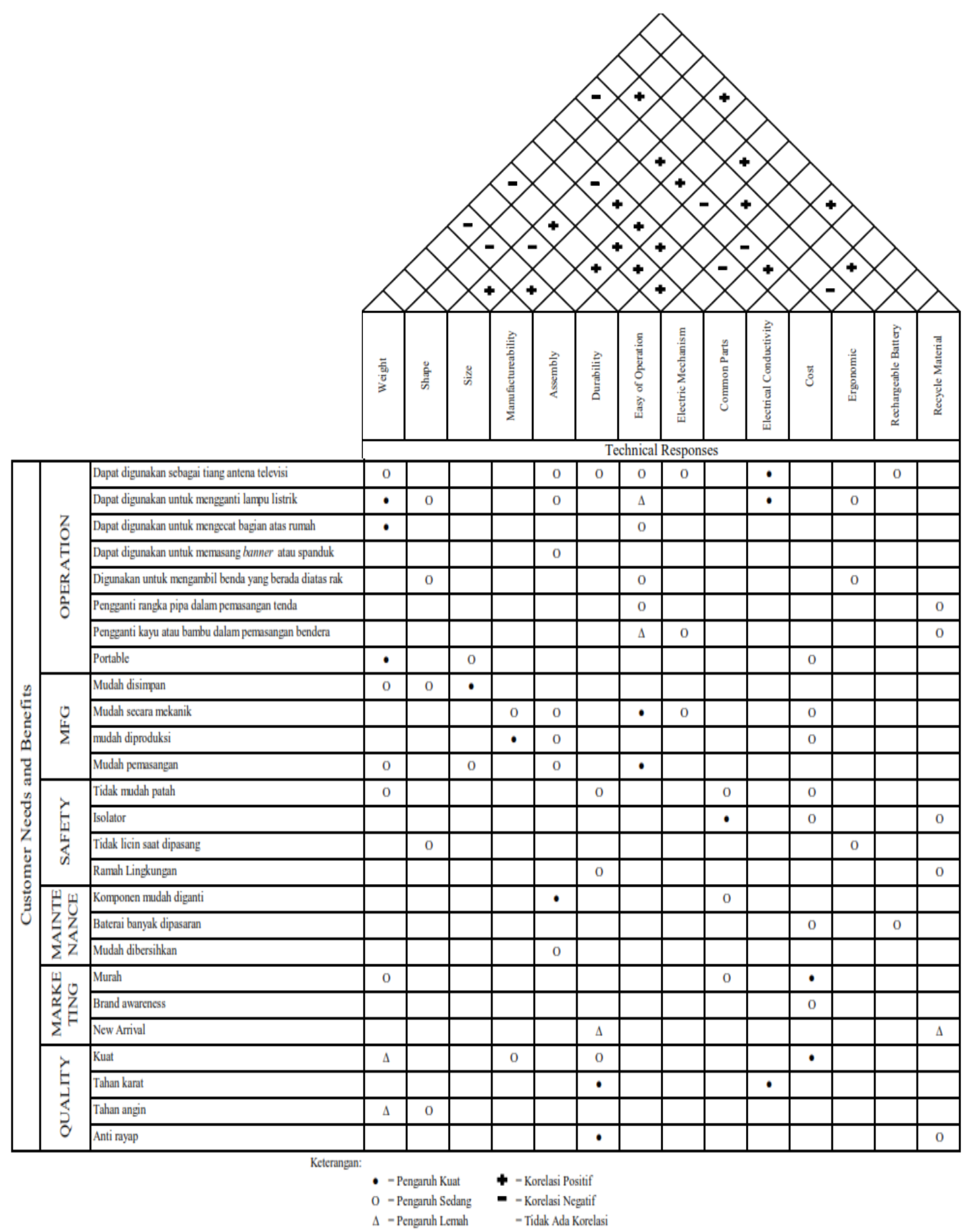

Gambar 3. House of Quality 
Tabel 1. Material properties untuk perencanaan pipa.

\begin{tabular}{lcc}
\hline Material Properties & HDPE & PVC \\
\hline Electrical Resistivity $(\Omega-\mathrm{m})$ & $10^{15}-5 \times 10^{16}$ & $>10^{14}$ \\
Density $\left(\mathrm{g} / \mathrm{cm}^{3}\right)$ & 0,959 & $1,30-1,58 \mathrm{~g} / \mathrm{cm}^{3}$ \\
Modulus of Elasticity $(\mathrm{GPa})$ & 1,08 & $2,41-4,14$ \\
Tensile Strength $(\mathrm{MPa})$ & $22,1-31,0$ & $40,7-51,7$ \\
Cost $(\mathrm{raw}$ form) $(\$ \mathrm{US} / \mathrm{kg})$ & $1,00-1,70$ & $1,40-2,80$ \\
\hline
\end{tabular}

Sumber: (Callister dan Rethwitch, 2014)

Tabel 2. Material properties untuk perencanaan pulley.

\begin{tabular}{lcc}
\hline Material Properties & PTFE & Aluminium \\
\hline Modulus of Elasticity (GPa) & $0,40-0,55$ & $63,70-76,10$ \\
Density $\left(\mathrm{g} / \mathrm{cm}^{3}\right)$ & 2,17 & $2,69-2,80$ \\
Strength $(\mathrm{MPa})$ & $20,7-34,5$ & $345-495$ \\
Cost (Raw Form) $(\$ \mathrm{US} / \mathrm{kg})$ & $20,00-26,5$ & $4,40-11,65$ \\
\hline
\end{tabular}

Sumber: (Callister dan Rethwitch, 2014)

Tabel 3. Material properties untuk perencanaan poros.

\begin{tabular}{lccc}
\hline \multicolumn{1}{c}{ Material } & Density $\left(\mathbf{M g} / \mathbf{m}^{\mathbf{3}}\right)$ & Strength $(\mathbf{M P a})$ & Relative Cost $\mathbf{( \$ \mathbf { ~ } )}$ \\
\hline Carbon fiber-reinforced composite & 1,5 & 1140 & 80 \\
Carbon fiber-reinforced composite & 2,0 & 1060 & 40 \\
Aluminium Alloy (2024-T6) & 2,8 & 300 & 15 \\
Titanium Alloy (Ti-6AI-4V) & 4,4 & 525 & 110 \\
4340 Steel & 7,8 & 780 & 5 \\
\hline
\end{tabular}

Sumber: (Callister dan Rethwitch, 2014)

2) Pulley. Berdasarkan kriteria yang diinginkan pada bagian 2, yaitu pulley yang ringan, kuat dan tidak kaku. Pada Tabel 2, menunjukkan dua jenis material pulley yang ada di pasaran, yaitu aluminium, dan PTFE (polytetraflourethylene) atau biasa dikenal dengan material jenis teflon. Berdasarkan Tabel 2, kriteria yang diinginkan yaitu material yang ringan, sehingga dipilih material jenis PTFE karena memiliki nilai density yang lebih rendah dibanding aluminium, karena semakin tinggi nilai density suatu material maka semakin tinggi nilai massa persatuan volume akan semakin tinggi pula. Namun dalam segi harga untuk PTFE jauh lebih mahal jika dibandingkan dengan aluminium. Pada segi kekuatan (strength) material untuk aluminium lebih tinggi jika dibandingkan dengan PTFE, namun strength aluminium yang lebih tinggi mengakibatkan material menjadi lebih kaku (rigid) sehingga tidak cocok digunakan untuk pulley yang secara fungsi membutuhkan keluwesan dalam melakukan putaran. Berdasarkan pertimbangan diatas, maka material PTFE atau teflon menjadi pilihan utama dalam pemilihan material untuk pulley.

3) Poros. Berdasarkan kriteria poros yang dikendaki yaitu kuat, ringan, dan murah. Maka, terdapat lima pilihan yang dapat dijadikan acuan. Pada Tabel 3, pilihan tersebut yaitu Carbon Fiber, Glass Fiber, Aluminium Alloy, Titanium Alloy, dan 4340 Steel. Tabel 3 menujukkan bahwa nilai Density yang rendah mengakibatkan material lebih ringan, nilai Strength yang tinggi mengakibatkan kekuatan material meningkat, serta Relative Cost yang rendah mengakibatkan biaya yang rendah. Kriteria poros yang diinginkan yaitu ringan, kuat, dan murah, maka yang dipilih yaitu material Carbon fiber-reinforced composite, karena material ini ringan, dan kuat, tetapi harga yang masih tinggi dibandingkan material yang lain, namun material ini dipilih karena secara fungsional yaitu 
ringan dan kuat, jauh lebih unggul dibandingkan yang lainnya.

c. Tahap Perencanaan Proses. Tahap ini dikenal dengan Process Deployment, yaitu perancangan yang telah dipilih berdasarkan kriteria, kemudian direncanakan Desain Produk (Product Design). Pada Tabel 4 menjelaskan Bill of Material tiap komponen yang dipilih. Komponen tersebut diperoleh dari vendor, dan dibuat secara customize karena ketiadaan vendor. Gambar 4 menunjukkan dimensi Shaft dan Gambar 5 menujukkan dimensi Pulley yang merupakan produk yang dibuat secara custumize yang telah disesuaikan dengan kebutuhan customer dan disesuaikan berdasarkan kebutuhan untuk di-assembly dengan part lain yang berhubungan (Bolt, Wire, dan Pipe)

d. Tahap Perencanaan Produksi. Tahap ini dikenal dengan Production Planning, yaitu merencanakan bagaimana produk ini diproduksi dengan bagaimana alur proses produksi tiap komponen tersebut. Pada tahap ini hanya merencanakan proses produksi komponan yang customize.

1) Perencanaan produksi poros.

a. Menggunakan mesin bubut, untuk pembubutan lurus dan ulir dengan ukuran M5.

b. Dilakukan pengerasan permukaan (surface hardening) dengan Heat Treatment.

2) Perencanaan produksi pulley.

a. Menggunakan mesin drilling, untuk proses pembuatan lubang pada raw material yang digunakan.

b. Menggunakan mesin bubut untuk membuat radius dengan lebar $8 \mathrm{~mm}$.

c. Dilakukan pengerasan permukaan (surface hardening) dengan Heat Treatment.

Tabel 4. Bill of Material tiap komponen

\begin{tabular}{llll}
\hline \multicolumn{1}{c}{ Part Name } & Specification & \multicolumn{1}{c}{ Supplier (Vendor) } & \multicolumn{1}{c}{ Cost } \\
\hline HDPE Pipe & $\varnothing 3$ Inch & PT. Wavin & Rp. 84,000/meter \\
Electric Motor & 12 Volt DC & PT. Surya Abadi Motor & Rp. 100,000/pcs \\
Battery & $3,7 \mathrm{~V}$ & PT. LG Technologies & Rp. 37,800 \\
Bolt & M5 & PT. Aoyama & Rp. 200/pcs \\
Steel Wire & $\varnothing 3 \mathrm{~mm}$ & CV. Kariwa & Rp. 10,000 \\
Pulley & & Customize & \\
Shaft (Poros) & & Customize & \\
\hline
\end{tabular}

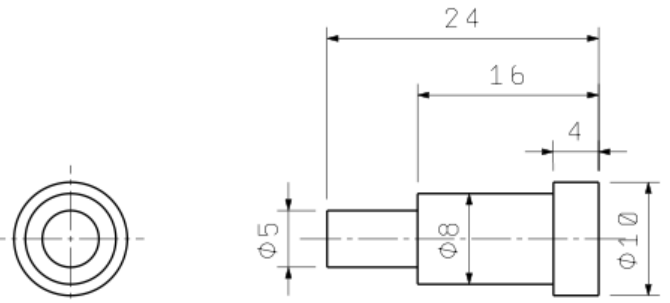

Gambar 4. Dimensi Shaft
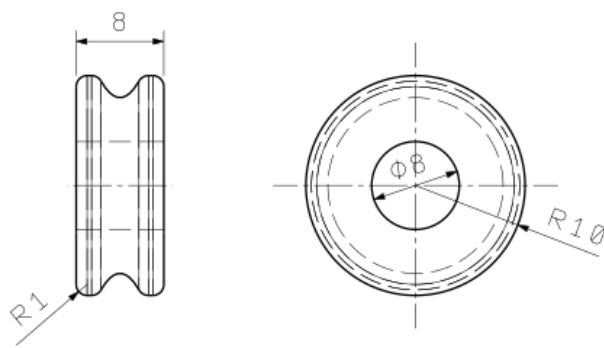

Gambar 5. Dimensi Pulley 


\section{KESIMPULAN}

Telecopstick merupakan alat inovatif yang dapat memanjang dan memendek sesuai kebutuhan, dengan penggerak electric motor. Alat ini memiliki banyak fungsi (multifungsi), sehingga memiliki added value yang lebih tinggi. Dalam perencanaan alat ini menggunakan metode QFD (Quality Function Deployment) yang berfokus pada Customer Requirement.

Berdasarkan hasil dari perencanaan menggunakan QFD, maka kesimpulan dari penelitian ini yaitu:

a. HOQ menunjukkan bahwa konsumen menginginkan alat yang memiliki kelebihan secara operational, kualitas yang baik dan memiliki safety yang baik. b. Tahap Perencanaan komponen, dipilih material HDPE untuk pipa, material PTFE untuk pulley, material carbon fiberreinforced composite untuk poros.

c. Tahap Perencanaan Proses, untuk semua komponen diperoleh melalui vendor dengan dimensi yang telah direncanakan terlebih dahulu. Untuk poros dan pulley dibuat secara customize dikarenakan ketiadaan vendor.

d. Tahap Perencanaan Produksi, pembuatan poros dilakukan menggunakan mesin bubut dan heat treatment, sedangkan untuk pembuatan pulley menggunakan mesin drilling, bubut dan heat treatment.

\section{DAFTAR PUSTAKA}

Anggraeni, M., Desrianty, A. dan Yuniar (2013) "Rancangan Meja Dapur Multifungsi Menggunakan Quality Function Deployment (QFD)," Reka Integra, 2(1), hal. 159-169.

Ashby, M. F. (2011) Material Selection in Mechanical Design. 4 ed. Oxford: Elsevier Ltd.

Callister, W. D. dan Rethwitch, D. G. (2014) Material Science and Engineering: An Introduction. 9 ed. New Jersey: John Wiley \& Sons.

Cohen, L. (1995) Quality Function Deployment: How to Make QFD Work for You. Massachusetts: Addison-Weasley Publication Company.

Hidayako, A. F. N. dan Betanursanti, I. (2017) "Desain Lemari Arsip di PT. Bank Rakyat Indonesia (BRI) Persero Tbk Cabang Gombong Menggunakan Metode Quality Function Deployment (QFD)," Spektrum Industri, 15(1), hal. 1-119.

Sakti, I. N., Purbawanto, S. dan Suryono (2013) "Modifikasi Antena Televisi Jenis Yagi sebagai Penguat Sinyal Modem Menggunakan Sistem Induksi," Jurnal Teknik Elektro Universitas Negeri Semarang, 5(1), hal. 32-28. 